\title{
Attitudes toward caring for dying patients: An overview among I talian nursing students and preliminary psychometrics of the FATCOD-B scale
}

\author{
Paolo Leombruni ${ }^{1}$, Marco Miniotti ${ }^{1}$, Andrea Bovero ${ }^{1}$, Francesca Zizzi ${ }^{1}$, Lorys Castelli ${ }^{2}$, Riccardo \\ Torta $^{1}$
}

1. Department of Neuroscience, University of Turin, Turin, Italy. 2. Department of Psychology, University of Turin, Turin, Italy.

Correspondence: Marco Miniotti. Address: Department of Neuroscience, University of Turin, 15, Via Cherasco, 10126, Turin, Italy. Email: mminiotti@cittadellasalute.to.it

Received: August 25, 2013

DOI : $10.5430 /$ jnep.v4n3p188
Accepted: September 27, 2013 Online Published: November 26, 2013

URL: http://dx.doi.org/10.5430/jnep.v4n3p188

\section{Abstract}

Background: Extensive research indicated that nursing students at the end of their curricula feel unprepared to care for the dying. Therefore, studies on nursing students' attitudes to caring for dying patients play a key role in nursing education, and the FATCOD-B scale is the only tool that specifically evaluates them.

Methods: A cross-sectional study design was used. During 2013, the FATCOD-B scale was administered to a sample of 82 nursing students. Descriptive statistics, the Student's $t$-test, Cronbach's alpha and principal components analysis were used in data analyses.

Results: Italian nursing students' scores on the FATCOD-B scale seemed to be lower than literature evidence on sums of ratings; however, mean ratings revealed similar levels of attitudes to the dying. Gender and personal experience with dying persons were not predictors of FATCOD-B scores. Internal consistency of the FATCOD-B scale was not satisfactory. Principal component analysis found a four-factor questionable solution for the FATCOD-B scale.

Conclusions: Findings from the present study suggest a need for end-of-life care nursing education in Italy. The preliminary results concerning the psychometrics of the scale suggest that the Italian version of the FATCOD-B could be in need of revision. The implications for practice are discussed.

\section{Key words}

Nursing students, End-of-life care, Attitudes toward the dying, FATCOD-B

\section{I ntroduction}

Like other health care providers, nurses are frequently exposed to death during their clinical work. However, the professional role of nurses means that they spend a lot of time at the bedside, and when a patient is terminally ill, nurses have to care for the patient's progressively worsening clinical condition as the patient approaches imminent death. Previous research in palliative care showed that dying patients experience a spectrum of needs that includes not only 
physical, psychological or spiritual wants, but also assistance with simple and basic daily activities, such as passing the time or shooting the breeze ${ }^{[1,2]}$. Meeting all these needs is a great endeavor for nurses it requires specific attitudes.

Unfortunately, studies on nurses' attitudes to caring for terminally ill persons showed that dealing with death and dying evokes negative emotions, such as feelings of helplessness or surrender, and creates fears, anxieties and anguishes that affect the quality of the care provided to patients ${ }^{[3-5]}$. A recent study reported that nurse assistants often described palliative care as a contrast to the everyday care they performed, in that they had a concrete possibility to provide the care the patient's needed ${ }^{[6]}$. Moreover, the study emphasized that nurse assistants felt uncomfortable talking about death with patients or with their relatives and that they needed help to address their own emotions ${ }^{[6]}$. Taken together, these results seem to suggest that an excellent care may not always be provided to dying patients and that the patients may have unmet needs. If this were true, research on end-of-life care education delivered within the nursing curriculum may play a key role in improving the end-of-life care provided.

Extensive research indicates that nursing students at the end of their curricula feel unprepared to cope with issues related to death, to care for dying patients and address grieving caregivers ${ }^{[3,7,8]}$. Many nursing students consider their curricula to be inadequate in teaching the end-of-life care and, more precisely, in providing the knowledge and in promoting the development of the attitudes required to care for dying patients ${ }^{[8-10]}$. The opinions given by nursing students on their own curricula have been confirmed by numerous studies aimed to identify the amount of contents on end-of-life care education provided throughout nursing curricula. These studies revealed minimal content on issues related to the end-of-life care and one of them showed that only $2 \%$ of undergraduate nursing textbooks addressed an end-of-life topic ${ }^{[11]}$. Even in spite of the recent increase of lectures on death and dying in many nursing programs, the end-of-life care education continues to play a minimal role in most cases ${ }^{[12]}$. Furthermore, this end-of-life care content is often delivered through traditional teaching methods, such as classroom lectures or small group discussions ${ }^{[3]}$. Such instruction methods do not provide students with the opportunity to experience their own reactions to directly facing the reality of palliative care ${ }^{[13]}$. Recent evidence from research on the theoretical basis and teaching methodology underlying nursing education emphasized the role of experiential learning and showed the efficacy of hospice visits, intensive didactic trainings and clerkships focused on death and care for the dying in developing the attitudes toward care of the dying ${ }^{[14-17]}$. Research findings suggest that nurses' attitudes to caring for the dying may influence the quality of the care they provided to patients at the end of their lives ${ }^{[18]}$. Moreover, this attitude-behavior association is thoroughly documented by a considerable amount of research ${ }^{[19]}$.

Therefore, considering the effects on the quality of care provided to patients, studies about attitudes to caring for the dying is an essential topic for nursing education research. To date, several studies have been conducted on nursing students' attitudes toward care of the dying and most of them used the Frommelt Attitude Toward Care of the Dying scale (FATCOD) ${ }^{[15,16]}$. The FATCOD is the only psychometric instrument that specifically detects nursing students attitudes' to caring for dying patients, as the assessment tool. However, few studies investigated the aspects of validity and reliability of the FATCOD scale ${ }^{[20,21]}$, and only one study has been conducted among Italian nursing students ${ }^{[22]}$. In particular, conflicting preliminary results emerged about the factor structure of the scale ${ }^{[20,21]}$.

So, the main aims of the present study are: a) to describe the Italian nursing students' attitudes to caring for the dying as measured by the FATCOD scale and compare the FATCOD scores with those obtained by medical students from the same university; b) to investigate the factor structure and psychometrics of the FATCOD scale.

\section{Methods}

\subsection{Study design}

The present study used a cross-sectional methodology to describe nursing students' attitudes toward care of the dying at one specific point in time, the beginning of the second year of their academic course, through a self-assessment carried out 
using a psychometric instrument. Ethical approval was obtained from the appropriate Ethical Review Committee. The study was conducted in accordance with the latest version of principles of the Declaration of Helsinki.

\subsection{Participants}

Study participants were second-year Italian nursing students. The total academic population of second-year nursing students $(\mathrm{N}=100)$ was invited to participate in the study, and the participants were properly informed about its purposes and methods. Of the total population, 82 students agreed to participate in the study and correctly completed the FATCOD scale questionnaire.

\subsection{I nstrument}

To investigate nursing students' attitudes toward the care of dying patients, the Frommelt Attitude Toward the Care of the Dying Scale form B (FATCOD-B) was used ${ }^{[16]}$. This self-report paper and pencil questionnaire consists of 30 randomly ordered items scored on a five-point Likert-type scale. Half of the statements are positively worded and half are negatively worded. The statements describe beliefs and feelings about end-of-life care, such as the patient's decision-making autonomy, the doctor's emotional involvement with the patient's experience, care of the patient's family and pain treatment. Positive items are scored as follows: $1=$ strongly disagree, $2=$ disagree, $3=$ uncertain, $4=$ agree, $5=$ strongly agree. Scores are reversed for negative items. The total score ranges from 30 to 150; higher scores indicate more positive attitudes.

\subsection{Procedures}

After a brief description of the study, questionnaires were administered to students at the beginning of their second year of nursing school. No time limit has been set for the completion of the questionnaire, and students took approximately 10 minutes to complete it. Responses were confidential and collected anonymously, and students identified themselves using nicknames. Each participant received an identification number when data were entered.

\subsection{Statistical analyses}

All statistical analyses were performed using SPSS for Mac, version 20.0. Descriptive statistics were calculated to summarize the data. Independent samples Student's $t$-tests were executed to examine the between-groups differences on the FATCOD-B scores. All statistical tests were two-tailed with the alpha set at 0.05 . Internal consistency was assessed calculating Cronbach's alpha. To identity the dimensions underlying the FATCOD-B items, the factor structure of the test was investigated. Cattel's Scree test was chosen as the criterion for factor retention ${ }^{[23]}$ and was used to determine the number of factors to extract. As variable-reduction, descriptive, technique, principal component analysis (PCA) with varimax rotation and Kaiser normalization was performed. The cut-off for size of loading to be interpreted was set at 0.40 , as generally accepted in personality research ${ }^{[24]}$. Loadings of 0.39 or lower were not considered for factors labeling.

\section{Results}

\subsection{Demographics}

Of the 82 participant students, $22(26.8 \%)$ were males and $60(73.2 \%)$ were females. The mean age was $21.46(\mathrm{SD}=1.13)$. Participants were asked to declare their eventual previous experiences with dying people, and $30(36.6 \%)$ students reported they had such personal experience (PED) while $52(63.4 \%)$ students reported they had no such personal experience (nPED).

\subsection{FATCOD-B scores description and psychometrics}

Participants scored 115.20 ( $\mathrm{SD}=7.86)$ on average on the FATCOD-B total score. No significant differences $(p=.857)$ were found between male $(114.93 \pm 7.78)$ and female $(115.28 \pm 7.97)$ students. Students who reported they had previous 
experiences with dying people $(117.22 \pm 7.57)$ outscored students who reported that having no such experience $(114.09 \pm$ $7.89)$, although this difference was not significant $(p=.083)$.

Table 1. Output of the Principal Component Analysis of the FATCOD-B Scale

\begin{tabular}{|c|c|c|c|c|c|c|}
\hline FATCOD-B items & $\mathbf{M} \pm \mathrm{SD}$ & $\mathbf{F} \mathbf{1}^{\mathrm{a}}$ & ${\mathrm{F} \mathbf{2}^{\mathrm{b}}}^{\mathrm{b}}$ & $\mathbf{F ~ 3}^{\mathbf{c}}$ & F $4^{\text {d }}$ & Com. $^{\mathrm{e}}$ \\
\hline Item 14. I am afraid to become friends with a dying person.* & $3.49 \pm 1.11$ & 0.68 & & & & 0.54 \\
\hline Item 15 . I would feel like running away when the person actually died.* & $3.94 \pm 0.79$ & 0.65 & & & & 0.47 \\
\hline Item 5. I would not want to care for a dying person.* & $4.14 \pm 0.95$ & 0.64 & & & & 0.54 \\
\hline $\begin{array}{l}\text { Item } 3 \text {. I would be uncomfortable talking about impending death with the dying } \\
\text { person.* }\end{array}$ & $2.20 \pm 0.83$ & 0.54 & & & & 0.44 \\
\hline Item 13. I would hope the person I'm caring for dies when I am not present.* & $3.78 \pm 0.86$ & 0.52 & & & & 0.32 \\
\hline Item 21 . It is beneficial for the dying person to verbalize his/her feelings. & $3.98 \pm 0.76$ & 0.51 & & & & 0.32 \\
\hline $\begin{array}{l}\text { Item } 11 . \text { When a patient asks, "Am I dying?" I think it is best to change the } \\
\text { subject to something cheerful.* }\end{array}$ & $3.86 \pm 0.84$ & 0.47 & & & & 0.38 \\
\hline $\begin{array}{l}\text { Item } 7 \text {. The length of time required giving care to a dying person would frustrate } \\
\text { me.* }\end{array}$ & $4.00 \pm 0.98$ & 0.43 & & & & 0.41 \\
\hline $\begin{array}{l}\text { Item } 17 \text {. As a patient nears death, the nonfamily caregiver should withdraw from } \\
\text { his/her involvement with the patient.* }\end{array}$ & $3.61 \pm 1.18$ & 0.43 & & & & 0.37 \\
\hline Item 12. The family should be involved in the physical care of the dying person. & $4.23 \pm 0.81$ & & & & & 0.20 \\
\hline $\begin{array}{l}\text { Item } 28 \text {. Educating families about death and dying is not a nonfamily caregiver } \\
\text { responsibility.* }\end{array}$ & $4.35 \pm 0.72$ & & 0.66 & & & 0.52 \\
\hline $\begin{array}{l}\text { Item } 6 \text {. The nonfamily caregivers should not be the one to talk about death with } \\
\text { the dying person.* }\end{array}$ & $4.01 \pm 0.93$ & & 0.60 & & & 0.46 \\
\hline $\begin{array}{l}\text { Item } 4 \text {. Caring for the patient's family should continue throughout the period of } \\
\text { grief and bereavement. }\end{array}$ & $4.11 \pm 0.79$ & & 0.59 & & & 0.41 \\
\hline Item 22. Care should extend to the family of the dying person. & $4.20 \pm 0.67$ & & 0.57 & & & 0.34 \\
\hline $\begin{array}{l}\text { Item } 19 \text {. The dying person should not be allowed to make decisions about his/her } \\
\text { physical care.* }\end{array}$ & $4.48 \pm 0.71$ & & 0.54 & & & 0.42 \\
\hline $\begin{array}{l}\text { Item 16. Families need emotional support to accept the behavior changes of the } \\
\text { dying person. }\end{array}$ & $4.41 \pm 0.66$ & & 0.53 & & & 0.34 \\
\hline Item 9. It is difficult to form a close relationship with the dying person.* & $3.48 \pm 1.03$ & & & & & 0.24 \\
\hline Item 27. Dying persons should be given honest answers about their condition. & $4.03 \pm 0.66$ & & & & & 0.09 \\
\hline Item 30 . It is possible for nonfamily caregivers to help patients prepare for death. & $4.25 \pm 0.66$ & & & & & 0.07 \\
\hline $\begin{array}{l}\text { Item 20. Families should maintain as normal an environment as possible for their } \\
\text { dying member. }\end{array}$ & $4.29 \pm 0.68$ & & & 0.73 & & 0.58 \\
\hline $\begin{array}{l}\text { Item } 24 . \text { The dying person and his/her family should be the in-charge } \\
\text { decision-makers. }\end{array}$ & $4.00 \pm 0.83$ & & & 0.72 & & 0.58 \\
\hline $\begin{array}{l}\text { Item 18. Families should be concerned about helping their dying member make } \\
\text { the best of his/her remaining life. }\end{array}$ & $4.49 \pm 0.71$ & & & 0.68 & & 0.52 \\
\hline Item 10. There are times when the dying person welcomes death. & $4.12 \pm 0.76$ & & & 0.63 & & 0.44 \\
\hline $\begin{array}{l}\text { Item } 25 \text {. Addiction to pain relieving medication should not be a concern when } \\
\text { dealing with a dying person. }\end{array}$ & $3.12 \pm 0.98$ & & & & 0.66 & 0.45 \\
\hline Item 2. Death is not the worst thing that can happen to a person. & $3.58 \pm 1.00$ & & & & 0.59 & 0.45 \\
\hline $\begin{array}{l}\text { Item } 8 \text {. I would be upset when the dying person I was caring for gave up hope of } \\
\text { getting better.* }\end{array}$ & $2.69 \pm 0.81$ & & & & 0.52 & 0.29 \\
\hline $\begin{array}{l}\text { Item } 29 \text {. Family members who stay close to a dying person often interfere with } \\
\text { the professional's job with the patient.* }\end{array}$ & $2.75 \pm 0.87$ & & & & -0.46 & 0.28 \\
\hline Item 1. Giving care to the dying person is a worthwhile experience. & $4.58 \pm 0.56$ & & & & 0.42 & 0.23 \\
\hline $\begin{array}{l}\text { Item } 26 . \text { I would be uncomfortable if I entered the room of a terminally ill person } \\
\text { and found him/her crying.* }\end{array}$ & $2.81 \pm 1.04$ & & & & -0.42 & 0.27 \\
\hline $\begin{array}{l}\text { Item 23. Caregivers should permit dying persons to have flexible visiting } \\
\text { schedules. }\end{array}$ & $4.17 \pm 0.72$ & & & & & 0.08 \\
\hline
\end{tabular}

Notes. Variables are ordered and grouped by size of loading to facilitate the understanding; Blank spaces indicate loadings of 0.39 or lower; *: Reverse items; ": Factor 1, "Emotional engagement", explains 10.5\% of variance; ${ }^{\text {b}: ~ F a c t o r ~ 2, ~ " B e l i e f s ~ a b o u t ~ e n d-o f-l i f e ~ c a r e ", ~ e x p l a i n s ~} 9.4 \%$ of variance; ': Factor 3, "Beliefs about professional boundaries", explains $9.0 \%$ of variance; ${ }^{\mathrm{d}}$ : Factor 4, "Beliefs and feelings about the dying" explains $8.3 \%$ of variance; ${ }^{\mathrm{e}}$ : Communality values. 
Item level statistics showed that the mean rating for the overall sample was 3.84 ( $\mathrm{SD}=0.26)$, which meant that, on average, students' responses were closest to the "agree" answer on the five-point Likert-type scale. Both males $(4.53 \pm$ $0.52)$ and females $(4.60 \pm 0.57)$ achieved the highest mean score on the directly scored item 1 (i.e., "Giving care to the dying person is a worthwhile experience") and obtained the lowest mean item score (2.40 \pm 1.06 and $2.14 \pm 0.76$, respectively) on the reverse scored item 3 (i.e., "I would be uncomfortable talking about impending death with the dying person”). Males ( $3.06 \pm 0.96)$ significantly outscored females $(2.58 \pm 0.73)$ on the reverse scored item 8 (i.e., "I would be upset when the dying person I was caring for gave up hope of getting better"). In contrast, females (4.25 \pm 0.66$)$ outscored males $(3.93 \pm 0.88)$ on the directly scored item 30 (i.e., "It is possible for nonfamily caregivers to help patients prepare for death").

PED students achieved the highest mean item score on item 1 while nPED students achieved the highest mean item score on the directly scored item 18 (i.e., "Families should be concerned about helping their dying member make the best of his/her remaining life"); both PED (2.39 \pm 0.84$)$ and nPED (2.09 \pm 0.82$)$ students obtained the lowest mean item score on item 3. No other significant differences between PED and nPED students were found at the item level.

Nursing students observed in the present study significantly outscored a sample of second-year medical students, with the same mean age and from the same university (sums of ratings $=112.78 \pm 8.00$; mean rating $=3.76 \pm 0.27 ; \mathrm{N}=193$ ) ${ }^{[26]}$, on the sums of ratings of the scale, expressed by the FATCOD-B total score $(p=.022)$.

\subsection{Factor structure of the FATCOD-B scale}

Due to the small sample size, the Kaiser-Meyer-Olkin (KMO) measure of sampling adequacy was conducted. The KMO test showed a mediocre value of 0.510 , and because this was greater than the cut-off of $0.5^{[25]}$, the PCA was performed. The Bartlett's test of sphericity showed a significance level of $<0.001$. The Cattell's Scree test showed that the slope of the line on which eigenvalues were plotted in component order tended to flatten after the point representing the fourth component. Therefore, four factors were extracted. This four-factor solution accounted for $37.2 \%$ of the total variance and the variables were not so well defined, as indicated by low communality values. After rotation and having set the cut-off for size of loading to be interpreted at 0.40 , a fairly clear pattern of factor loadings emerged. Factor I was defined by nine items and labeled as "Emotional engagement". Factor II was defined by six items and labeled as "Beliefs about end-of-life care". Factor III was defined by four items and labeled as "Beliefs about professional boundaries". Factor IV was defined by six items and labeled as "Beliefs and feelings about dying". The rotated factor matrix is reported in Table 1.

\subsection{Reliability}

The internal consistency of the FATCOD-B was questionable. Cronbach's alpha was 0.68 for the entire scale, 0.72 for Factor I, 0.68 for Factor II, 0.71 for Factor III and 0.11 for Factor IV. Excluding Factor IV and items 12, 9, 27 and 30 (the items with loadings below the cut-off of 0.40 on the PCA), Cronbach's alpha increases up to the acceptable value of 0.72 .

\section{Discussion}

Findings from the present study provide an overview of Italian nursing students' attitudes toward caring for dying patients and of the psychometrics of the FATCOD-B scale. Considering, a) the lack of previous research about end-of-life care education's topics in the Italian context and b) preliminary conflicting results concerning the FATCOD-B scale's psychometric properties, the present study contributes to reducing the gap in and to discussing the results from the literature, respectively.

The present study is subject to several limitations. First of all, the sample size is small. Although the KMO test and the Bartlett's test of sphericity are generally accepted measures of sampling adequacy, to perform a reliable PCA, it is recommended that there be five cases per variable. Therefore, the results on the FATCOD-B factor structure (and the 
FATCOD-B scores, as well) found in the present study should be considered with caution and cannot be generalized. Secondly, the lack of normative data or cut-off values in literature about FATCOD-B scores' distribution means that findings from the present study are not directly understandable. To reduce this limitation, we compared our findings with those of similar previous studies. Thirdly, using a cross-sectional methodology prevents us from conducting longitudinal observations and subsequently performing repeated measures. Therefore, we have not calculated the intra-class correlation coefficient to explore the test-retest reliability of the scale, an important property of a psychometric instrument. Lastly, the absence of a control group represents an unquestionable methodological limit.

Despite the aforementioned limitations, the present study reported interesting observations that deserve to be discussed.

When compared with recent research evidence on nursing students' attitudes toward caring for dying patients as measured by the FATCOD-B ${ }^{[9,21]}$, the scores we observed seem to be quite low. Findings from studies conducted among American $(123.7 \pm 11.43 ; \mathrm{N}=59){ }^{[9]}$ and Swedish $(125.5 \pm 8.2 ; \mathrm{N}=100){ }^{[22]}$ nursing students reported significantly higher total scores than those obtained among Italians $(p \leq .001 ; p \leq .001$, respectively). However, these differences, expressed in mean ratings, correspond to changes of between 0.28 and 0.34 points on the five-point rating scale. Focusing on the units of the rating scale, these little shifts reflect small differences in practical terms because they are approximately equidistant from the 4-point response, which means "agree". Nevertheless, the lack of normative data and the age difference between groups do not allow for further discussion of these results.

Regarding the effect of gender on FATCOD-B scores, our findings corroborate previous research conducted on undergraduate nursing students ${ }^{[21]}$, medical students ${ }^{[26,27]}$ and nurses ${ }^{[5,16]}$. In general, gender was not found to be a significant predictor of attitudes toward the care of dying patients. However, evidence in the literature showed gender differences among medical students (where females showed more positive attitudes than males) on several peculiar aspects of attitudes toward end-of-life care, such as providing psychological support for family caregivers during both end-of-life care and bereavement ${ }^{[27]}$. Interestingly, both males and females in the present study achieved the highest mean score on the directly scored item 1 (i.e., "Giving care to the dying person is a worthwhile experience"). Being still undergraduate students, this is an encouraging result for the prospect of their careers. On the other hand, students obtained the lowest mean score on the reverse scored item 3 (i.e., "I would be uncomfortable talking about impending death with the dying person"). This finding may reflect feelings of poor confidence in self-efficacy, due to the perception of helplessness, which is often observed among nurses ${ }^{[6]}$.

Regarding the effect of personal experiences with terminally ill people on attitudes toward caring for the dying, our findings corroborate previous observations on nurses ${ }^{[21]}$ and medical students ${ }^{[26]}$. Although in the present study students who had personal experience with dying persons showed more positive attitudes than did students who had no such experience, the differences we observed were small in absolute terms and not significant in any case. As shown by several previous studies ${ }^{[21,26]}$, meeting dying persons did not predict attitudes toward end-of-life care. In our opinion, these observations may reflect a psychological mechanism by means of which students protected themselves from distressing memories. In fact, being young adults, it is very likely that dying persons who they met may have been relatives or friends. This hypothesis could be supported by other evidence in the literature that showed how the age and the amount of exposure to dying patients were positively associated with nurses' attitudes toward the care of the dying. However, the small sample size of the present and previous studies ${ }^{[21,26]}$ does not allow us to draw a conclusion on this apparent effect.

To our knowledge, this is the first study that compared undergraduate nursing and medical students on FATCOD-B scores. Therefore, it is difficult to discuss the findings we observed. Though the findings would be significant if expressed by rating sums, we can only argue that the between-groups difference we found on the FATCOD-B total score is very weak considering the mean rating values (a gap of 0.08-point on the rating scale). We can conclude that there is a reason to conduct an investigation at the item level by exploring the possible between-groups differences on the different aspects of attitudes toward the care of the dying considered by the FATCOD-B scale. 
Our findings about the FATCOD-B factor structure are questionable. Although the FATCOD-B scale has been conceptualized as a single dimension ${ }^{[15,16]}$, the Japanese validation study conducted by Nakai and colleagues ${ }^{[20]}$ found a two-factor solution for the PCA they performed. This study was the first to explore the factor structure of the FATCOD-B, and proposed a new conceptualization for the scale composed of two independent dimensions they called FATCOD I (relating to positive attitudes toward caring for the dying patient) and FATCOD II (relating to perceptions of patient- and family-centered care). The authors performed a PCA without a fixed number of factors to extract and used a criterion based on eigenvalues $>1$ to find a seven-factor solution, accounting for $54 \%$ of the total variance. Based on the interpretation of the meanings of factors, they conceptually merged them as follows: factor V, factor IV and factor II were joined in FATCOD I; factor VI, factor III and factor I were joined in FATCOD II; factor VII (corresponding to item 10 of the FATCOD-B scale) was excluded. Although this may be an acceptable solution, its nature is conceptual and not sustained enough by the data. The conceptualization of Nakai and colleagues was used, without further investigations, in subsequent studies in Japan and has been found useful in describing between-groups differences in attitudes ${ }^{[28,29]}$. Nevertheless, in a recent Swedish validation study ${ }^{[21]}$, Henoch and colleagues performed a PCA with 2 factors to extract, in order to examine whether the conceptualization proposed by Nakai and colleagues could also be acceptable on a different sample. The authors reported that the results of the PCA (that explained $22.8 \%$ of the total variance) were similar but not identical to those found in the Japanese validation study; they called the factors they extracted FATCOD I_Swe and FATCOD II_Swe. Also the Cronbach's alpha values, although fairly low, were comparable to each other ${ }^{\text {[21] }}$. Given these results, Henoch and colleagues concluded that the two subscales may be used with caution with the Swedish version of the FATCOD scale, but that, for the time being, the single dimension solution is the most adequate for use in Sweden ${ }^{[21]}$. In contrast to Henoch and colleagues, we only preferred to explore the factor structure of the FATCOD-B scale on a sample of Italian nursing students and thus we performed a PCA with a fixed number of factors to extract only after having observed the Cattel's Scree test's output. Although the criteria for a useful variable-reduction technique were met, the four-factor solution we described was not satisfactory. The four principal components we extract accounted for $37.2 \%$ of the variance in the original variables and the calculation of the internal consistency achieved the recommended criterion of 0.70 for only Factor I and Factor III. However, the pattern of factor loadings we observed was fairly clear and the loading values found in the present study seem to be higher than those found in the Swedish validation study ${ }^{[21]}$ and quite similar to those found by the Japanese research team ${ }^{[20]}$. We did not calculate any differences because the means of the loadings of the two different factor solution were not directly comparable. Furthermore, with the exception of Factor IV, the internal consistency calculated for each factor extracted was greater than that observed in the Swedish study ${ }^{[21]}$ and quite similar to those found by Nakai and colleagues ${ }^{[20]}$. Finally, we believe that the conceptualization provided by factors interpretation found in the present study may be interesting and useful in further research. Somehow, the feelings/beliefs model we are discussing seems to recall the original concept of attitude as defined by Eagly and Chaiken ${ }^{[30]}$. These authors defined attitudes as psychological tendencies arising from beliefs and giving rise to feelings that promotes behaviors toward someone or something. In our opinion, the four-dimension solution we proposed could well respect the theoretical framework behind the concept of attitude.

\section{Conclusion}

Taken together, findings from the present study seem to suggest several implications for practice. First, there is a still present need for nursing education on care of the dying and on all of the end-of-life aspects and issues, even in Italy. Further research is needed to define all the predictors that could potentially influence the attitudes toward the care of dying persons in a specific environment and to plan tailored teaching programs in nursing curricula. Considering evidence from the literature ${ }^{[26,27]}$, these reflections are desirable both for nursing and medical students, at least in Italy. Secondly, at the present time, the FATCOD-B scale is the only psychometric tool to evaluate the attitudes toward the care of the dying and the outcome of a specific training on these attitudes. The preliminary results concerning the psychometrics of the scale found in the present study seem to suggest that the Italian version of the FATCOD-B could be in need of revision. The four-dimension solution used in the present study must be explored on a larger sample and evaluated with full criteria of 
psychometrical reliability. Therefore, considering the aforementioned implications for practice, there is a great need for further studies that ascertain the complete reliability of the Italian version of FATCOD-B scale.

\section{References}

[1] Harrison JD, Young JM, Price MA, Butow PN, Solomon MJ. What are the unmet supportive care needs of people with cancer? A systematic review. Support Care Cancer. 2009; 17(8): 1117-1128. PMid:19319577 http://dx.doi.org/10.1007/s00520-009-0615-5

[2] Osse BH, Vernooij-Dassen MJ, Schadé E, Grol RP. The problems experienced by patients with cancer and their needs for palliative care. Support Care Cancer. 2005; 13(9): 722-732. PMid:15702349 http://dx.doi.org/10.1007/s00520-004-0771-6

[3] Gillan PC, van der Riet PJ, Jeong S. End of life care education, past and present: A review of the literature. Nurse Educ Today. 2013; doi:pii: S0260-6917(13)00209-8. 10.1016/j.nedt.2013.06-009.

[4] Gama G, Barbosa F, Vieira M. Factors influenced nurses' attitudes toward death. Int J Palliat Nurse. 2012; 18(6): 267-273. PMid:22885899

[5] Lange M, Thom B, Kline NE. Assessing nurses' attitudes toward death and caring for dying patients in a comprehensive cancer center. Oncol Nurs Forum. 2008; 35(6): 955-959. PMid:18980927 http://dx.doi.org/10.1188/08.ONF.955-959

[6] Beck I, Törnquist A, Broström L, Edberg AK. Having to focus on doing rather than being-nurse assistants' experience of palliative care in municipal residential care settings. Int J Nurs Stud. 2012; 49(4): 455-464. PMid:22079261 http://dx.doi.org/10.1016/j.jinurstu.2011.10.016

[7] Gibbons C, Dempster M, Moutray M. Stress, coping and satisfaction in nursing students. J Adv Nurs. 2011; 67(3): 621-632. PMid:21077931 http://dx.doi.org/10.1111/j.1365-2648.2010.05495.x

[8] Wallace M, Grossman S, Campbell S, Robert T, Lange J, Shea J. Integration of end-of-life care content in undergraduate nursing curricula: student knowledge and perceptions. J Prof Nurs. 2009; 25(1): 50-56. PMid:19161963 http://dx.doi.org/10.1016/j.profnurs.2008.08.003

[9] Mallory JL. The impact of a palliative care educational component on attitudes toward care of the dying in undergraduate nursing students. J Prof Nurs. 2003; 19(5): 305-312. http://dx.doi.org/10.1016/S8755-7223(03)00094-2

[10] Lloyd-Williams M, Field D. Are undergraduate nurses taught palliative care during their training? Nurse Educ Today. 2002; 22(7): 589-592. PMid: 12384040

[11] Ferrell B, Virani R, Grant M, Juarez G. Analysis of palliative care content in nursing textbooks. J Palliat Care. 2000; 16(1): 39-47. PMid:10802963

[12] Barrere CC, Durkin A, LaCoursiere S. The influence of end-of-life education on attitudes of nursing students. Int J Nurs Educ Scholarsh. 2008; 5(1): 1-18. PMid:18384269 http://dx.doi.org/10.2202/1548-923X.1494

[13] Mok E, Lee WM, Wong FK. The issue of death and dying: employing problem-based learning in nursing education. Nurs Educ Today. 2002; 22(4): 319-329. PMid:12030753 http://dx.doi.org/10.1054/nedt.2001.0708

[14] Kwekkeboom KL, Vahl C, Eland J. Impact of a volunteer companion program in nursing students' knowledge and concerns related to palliative care. J Palliat Med. 2006; 9(1): 90-99. PMid:16430349 http://dx.doi.org/10.1089/jpm.2006.9.90

[15] Frommelt KH. The effects on death education on nurses' attitudes toward caring for terminally ill persons and their families. Am J Hosp Palliat Care. 1991; 8(5): 37-43. PMid:1742142 http://dx.doi.org/10.1177/104990919100800509

[16] Frommelt KH. Attitudes toward care of the terminally ill: an educational intervention. Am J Hosp Palliat Care. 2003; 20(1): 13-22. PMid:12568433 http://dx.doi.org/10.1177/104990910302000108

[17] Dobbins EH. The impact of end-of-life curriculum content on the attitudes of associate degree nursing students toward death and care of the dying. Teach Learn Nurs. 2011; 6(4): 159-166. http://dx.doi.org/10.1016/j.teln.2011.04.002

[18] Peters L, Cant R, Payne S, O'Connor M, McDermott F, Hood K et al. How death anxiety impact nurses' caring for patients at the end of life: a review of literature. Open Nurs J. 2013; 7: 14-21. PMid:23400515 http://dx.doi.org/10.2174/1874434601307010014

[19] Wallace DS, Paulson RM, Lord CG, Bond CF. Which behaviors do attitudes predict? Meta-analyzing the effects of social pressure and perceived difficulty. Review Gen Psychol. 2005; 9: 214-227. http://dx.doi.org/10.1037/1089-2680.9.3.214

[20] Nakai Y, Miyashita M, Sasahara T, Koyama Y, Shimzu Y, Kawa M. Factor structure and reliability of the Japanese version of the Frommelt attitude toward care of the dying scale (FATCOD-B-J). [in Japanese]. Jpn J Cancer Nurs. 2006; 11(6): 723-729.

[21] Henoch I, Browall M, Melin-Johansson C, Danielson E, Udo C, Johansson Sundler A et al. The Swedish Version of the Frommelt Attitude Toward Care of the Dying Scale: Aspects of Validity and Factors Influencing Nurses' and Nursing Students' Attitudes. Cancer Nurs 2013; http://dx.doi.org/10.1097/NCC.0b0013e318279106b. [Epub ahead of print].

[22] Mastroianni C, Piredda M, Frommelt KHM, Mirabella F, Taboga C, Casale G et al. Italian validation of the Froomelt Attitudes Toward Care Of the Dying Scale form B (FATCOD Form B-I). Int Nurs Perspect. 2009; 9(1): 11-16. 
[23] Cattell RB. The scree test for the number of factors. Multivariate Behav Res. 1966; 1: 245-276. http://dx.doi.org/10.1207/s15327906mbr0102_10

[24] Laher S. Using exploratory factor analysis in personality research: best practice and recommendations. SA Journal of Industrial Psychology. 2010.

[25] Kaiser HF. An index of factorial simplicity. Psychometrika. 1974; 39: 31-36. http://dx.doi.org/10.1007/BF02291575

[26] Leombruni P, Miniotti M, Bovero A, Castelli L, Torta RG. Second-year Italian medical students' attitudes toward care of the dying patient: an exploratory study. J Canc Educ. 2012; 27(4): 759-763. PMid:22653400 http://dx.doi.org/10.1007/s13187-012-0382-8

[27] Leombruni P, Miniotti M, Torta RG. Personality and attitudes towards dying patients: An Italian pilot study among medical students. Med Teach 2013; [Epub ahead of print]. PMid:23607519 http://dx.doi.org/10.3109/0142159X.2013.786809

[28] Miyashita M, Nakai Y, Sasahara T, Koyama Y, Shimzu Y, Tsukamoto N et al., Nursing autonomy plays an important role in nurses' attitudes toward caring for dying patients. Am J Hosp Palliat Care. 2007; 24(3): 202-210. PMid:17601844 http://dx.doi.org/10.1177/1049909106298396

[29] Matsui M, Braun K. Nurses' and care workers' attitudes toward death and caring for older adults in Japan. Int J Palliat Nurs. 2010; 16(12): 593-598. PMid:21240103

[30] Eagly AH, Chaiken S. The psychology of attitudes. Forth Worth, TX; ed. Harcourt Brace Jovanovich, 1993. 